\title{
Glyconeogenesis in Growing and Non-growing Cultures of Tetrahymena pyriformis
}

\author{
BY M. R. LEVY* AND O. H. SCHERBAUM \\ Department of Zoology, University of California, Los Angeles, \\ California, U.S.A.
}

(Received 29 July 1964)

\begin{abstract}
SUMMARY
The glycogen content of peptone grown cultures of the ciliate Tetrahymena pyriformis GL, increased from $6 \%$ cellular protein during the exponential growth phase to $30 \%$ or more in the stationary phase of growth. The oxygen content in the medium began to decrease at a population of 7500 organisms $/ \mathrm{ml}$. in gently shaken cultures and at 80,000 organisms/ ml. in well aerated cultures. In either case, depletion of oxygen in the medium was soon followed by cessation of multiplication. The stationary phase was rapidly induced by transfer of log phase organisms to conditions of restricted aeration. Within $3 \mathrm{hr}$ after such a transfer, the rate of glyconeogenesis approximately doubled, both in cultures and in washed suspensions of organisms incubated with $0.1 \%$ sodium acetate.
\end{abstract}

\section{INTRODUCTION}

Non-growing cultures of micro-organisms have frequently been shown to accumulate reserves of lipids or polysaccharides (Wilkinson, 1959, 1963). Most commonly found are poly- $\beta$-hydroxybutyrate and glycogen or glycogen-like polymers. Accumulation of such polymers usually occurs when growth is limited by factors other than by a carbon source. Thus, with Escherichia coli, polysaccharide accumulation was greatest after the onset of the stationary phase of growth, or when the rate of synthesis of nitrogen containing compounds was slow (Dagley \& Dawes, 1949; Holme \& Palmstierna, 1955, 1956). Similarly, in Klebsiella aerogenes the cellular polysaccharide content was higher when growth was limited by a deficiency in nitrogen, phosphorus, or sulphur, rather than a carbon source (Duguid \& Wilkinson, 1953).

Manners \& Ryley (1952) reported a glycogen content of as much as $23 \%$ of the dry weight in stationary phase peptone-grown cultures of the ciliate protozoan Tetrahymena pyriformis. The purified product resembled mammalian glycogen in various chemical and physical properties. Further studies by Ryley (1952) showed that this polysaccharide could serve as an energy reserve material for the organisms when anaerobically incubated.

Stationary phase cultures of Tetrahymena when aerated adequately can perform glyconeogenesis at high rates (Hogg \& Wagner, 1956; Warnock \& van Eys, 1962). Thus, Hogg \& Wagner (1956) found that washed stationary phase organisms of

* Present address: Department of Chemistry, Queens College of the City University of New York, Flushing, New York. 
Tetrahymena pyriformis strain E, doubled their glycogen content at the expense of other endogenous reserves. The observed decrease in the lipid and protein content of the organisms was sufficient to account for the glycogen accumulation. Addition of butyrate, acetoacetate, or acetate to the suspension greatly stimulated the rate of glyconeogenesis. Later, Hogg \& Kornberg (1963) invoked the glyoxylate cycle to account for the observed glyconeogenesis.

The present paper describes the glycogen content of Tetrahymena pyriformis GL and the oxygen content of the medium during a normal growth cycle, with emphasis on the glyconeogenic capacity during experimentally induced stationary phase. A preliminary report has been presented (Levy, Scherbaum \& Hogg, 1964).

\section{METHODS}

Organism and growth conditions. Tetrahymena pyriformis strain GL, was grown in a peptone medium of the following composition: $2 \%(w / v)$ proteose peptone (Difco), $0 \cdot 1 \%(w / v)$ liver fraction 2 N.F. (Wilson Laboratories, Chicago, Illinois). Sulphates and chlorides were added as in the basal medium $\mathbf{A}$ of Kidder \& Dewey (1951). In more recent experiments, the only inorganic salt added was $0 \cdot 1 \%(w / v) ~ \mathbf{K}_{2} \mathbf{H P O}_{4}$. Stock cultures were maintained at $17^{\circ}$ in $10 \mathrm{ml}$. medium in cotton-stoppered upright test tubes $(18 \times \mathbf{1 5 0} \mathrm{mm}$.). For inoculation of experimental cultures, $1 \mathrm{ml}$. portions of the tube cultures, 3-4 days old, were transferred to $50 \mathrm{ml}$. medium in $250 \mathrm{ml}$. Erlenmeyer flasks. After incubation for 24-48 hr, samples (3-10 ml.) were used for inoculating each litre of the experimental cultures. To achieve maximum aeration, these cultures were grown in 1 to $1.5 \mathrm{l}$. batches in a stainless steel tank with surface dimensions of $42 \times 80 \mathrm{~cm}$. (Scherbaum, James \& Jahn, 1959). The tank was gently tilted about its minor axis (18 strokes/min.) to ensure proper aeration of the 3.0-4.5 mm. layer of culture medium. Sterile water-saturated air replenished the air phase of the culture vessel at a rate of $31 . / \mathrm{min}$. Organisms were incubated at $28^{\circ}$ or at room temperature $\left(24^{\circ}-28^{\circ}\right)$, In some cases, cultures of $300-1500 \mathrm{ml}$. were grown in 2.5 l. low-form culture flasks shaken by rotatory movements at 60 to 80 oscillations/min.

Harvesting of organisms. Cultures were centrifuged in $40 \mathrm{ml}$. conical tubes at 250-300 $\mathrm{g}$ for $1.5 \mathrm{~min}$., the supernatant fluid removed by suction and the organisms washed at least twice by resuspension in $40 \mathrm{ml}$. Ringer phosphate buffer (Ryley, 1952). Large samples of suspensions were centrifuged in $600 \mathrm{ml}$. centrifuge flasks for 5 min. at $250 \mathrm{~g}$ in an International Centrifuge, model PR2. The flasks were specially designed to facilitate collection of the organisms in a bulb-like extension in the centre of the funnel-shaped bottom. Organisms were then washed as described above. When the glycogen content was to be determined in culture samples, measured volumes of culture were poured directly into cold ethanol to a final concentration of $35 \%(\mathrm{v} / \mathrm{v})$ ethanol. The organisms were collected by centrifugation at $150 \mathrm{~g}$ for $5 \mathrm{~min}$., and the supernatant fluid removed by suction and discarded.

Analytical methods. Dissolved oxygen was measured by the volumetric method of Scholander, van Dam, Claff \& Kanwisher (1955). To insure rapid fixation of organisms, $4 \%(\mathrm{v} / \mathrm{v})$ formalin $(40 \%, \mathrm{w} / \mathrm{v}, \mathrm{HCHO})$ was added to the buffer solution present in the dead space of the extraction syringe. Glycogen was isolated by the method of Good, Kramer \& Somogyi (1933). Radioactive glycogen was purified 
either by two precipitations in ethanol, followed by washings, twice each, in $80 \%$ (v/v) and $100 \%$ ethanol and anhydrous ether, or alternatively by successive precipitation by $50 \%$ alkaline ethanol, $67 \%$ acidic ethanol, and $75 \%$ ethanol. A few milligrams of sodium sulphate were added to each sample to aid in precipitation. Glycogen was estimated by an anthrone method (Morris, 1948) with some modifications. Samples were frozen in a solid $\mathrm{CO}_{2}+$ ethanol bath, and two volumes of anthrone reagent ( $2 \mathrm{mg}$. anthrone $/ \mathrm{ml}$. concentrated sulphuric acid) were added to the frozen samples. These were then allowed to melt in a boiling water bath. Protein was determined by the Lowry method, as modified by Chou \& Goldstein (1960), on material insoluble after digestion in $3 \%(\mathrm{w} / \mathrm{v})$ perchloric acid for $15 \mathrm{~min}$. at $90^{\circ}$.

Radioactive samples were counted at infinite thinness on stainless steel or nickelplated planchet in a thin window gas flow counter (Nuclear Chicago). Counting rates have been corrected for background. ${ }^{14} \mathrm{C}$ labelled acetate was obtained from the California Corporation for Biochemical Research.

Direct counts of organisms were made, in formalin-fixed samples, in a SedgewickRafter counting chamber with the aid of a calibrated ocular Whipple dise in a light microscope at a magnification of $\times 100$ (Scherbaum, 1957).

\section{RESULTS}

Glycogen content in log phase and stationary phase organisms

Cultures (1.5 1.) were grown in the stainless steel vessel either shaken and aerated, or not shaken but aerated. All other conditions (composition of medium, age and size of inoculum, etc.) were identical. The generation time of about $3 \mathrm{hr}$ was the same for both cultures during exponential multiplication, but the final population densities in the stationary phase differed significantly. In the shaken culture, it was more than $10^{6}$ organisms $/ \mathrm{ml}$.; in the non-shaken culture, it was only between 1 and $2 \times 10^{5}$ organisms $/ \mathrm{ml}$. Cultures of the latter type were used for further experiments. Either shaking such cultures or transfer to an inorganic buffer permitted further growth for at least one generation. It appears that in this type of stationary phase, nutrients were not limiting and were still available for conversion into storage products.

The glycogen content of organisms in the exponential growth phase was between 3 and $12 \%$ of cellular protein (40 samples; average $6 \%$ ) and 25 and $40 \%$ (17 samples; average $30 \%$ ) in stationary phase organisms. Calculated per $10^{6}$ organisms, those values were $0 \cdot 05-0 \cdot 150 \mathrm{mg}$. in $\log$ phase and $0 \cdot 8-2 \cdot 0 \mathrm{mg}$. in stationary phase.

\section{Culture growth and oxygen content of the medium}

Two 1.5 l. cultures were grown in $2.5 \mathrm{l}$. low-form culture flasks. One flask was shaken vigorously and aerated, while the second was shaken very gently so that no trapping of air could occur at the surface. The second culture was not initially aerated, although air could pass into the vessel by diffusion through a cotton-wool plug. From these cultures, samples were removed at frequent intervals for total counts and determination of dissolved oxygen in the medium. The oxygen content before inoculation was $4 \cdot 8 \mu \mathrm{l}$./ml. culture.

In the well-aerated culture (Fig. $1 \mathrm{~A}$ ) the oxygen content had decreased to $3 \mu \mathrm{l} . / \mathrm{ml}$. 
medium at a population density of about 80,000 organisms $/ \mathrm{ml}$. and became undetectable at about 350,000 organisms $/ \mathrm{ml}$. The final population density was over 700,000 organisms $/ \mathrm{ml}$. In the non-aerated culture, however, the oxygen content was $3 \mu \mathrm{l} . / \mathrm{ml}$. already at a population density of $7,500 \mathrm{organisms} / \mathrm{ml}$. and became undetectable at $\mathbf{3 0 , 0 0 0}$ organisms $/ \mathrm{ml}$. (Fig. 1B). The maximum population density remained constant at 90,000 organisms $/ \mathrm{ml}$. for $20 \mathrm{hr}$. At this time, flushing of the air phase was started (indicated by the arrow in Figure 1B), but the shaking rate was not altered. After a lag period of $10 \mathrm{hr}$, multiplication was resumed and continued slowly until the population density had approximately doubled. In another non-aerated control culture, the population density in the stationary phase remained constant at 110,000 organisms/ml. for several days.
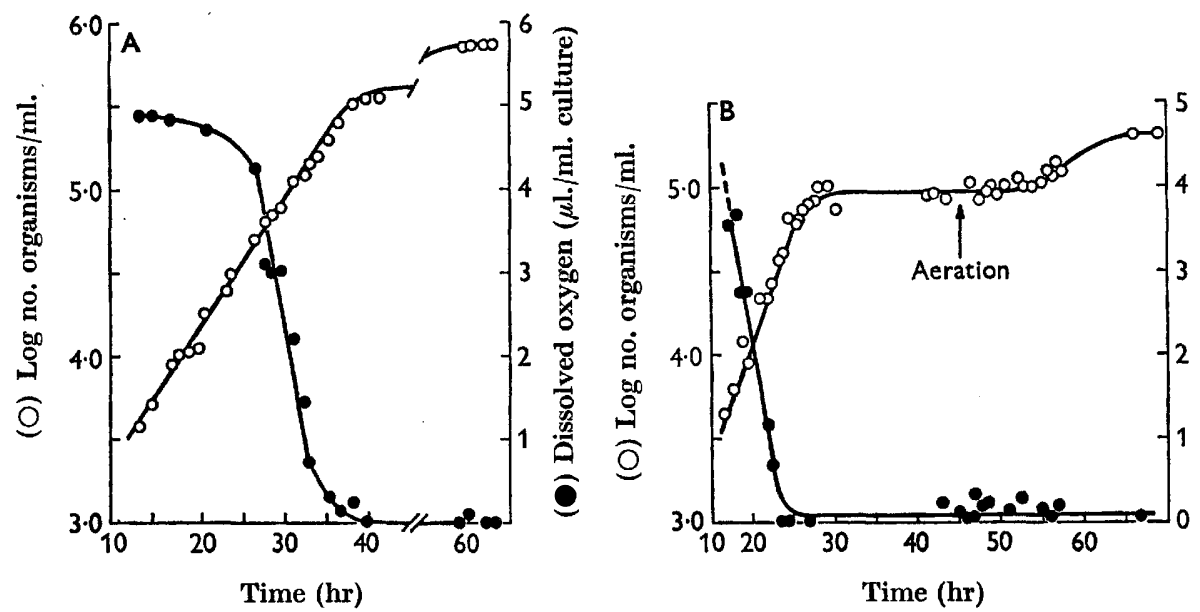

Fig. 1. Oxygen content of the medium during culture growth. Organisms were grown in $2 \cdot 5$ l. low-form culture flasks at $28^{\circ} \pm 1^{\circ}$; surface area approximately $450 \mathrm{~cm}^{2}$. A. Flask was vigorously shaken (70-90 oscillations/min.) and air was continuously flushed over the culture. Initial culture volume was $1 \cdot 21$. B. Culture was shaken gently so as to prevent surface disturbance. Aeration of the culture was begun at the point indicated by the arrow; however, the rate of shaking was not changed. Initial culture volume was 1.51 .

The respiratory capacity of the cultures was compared with the availability of oxygen in the non-aerated culture. At a population density of 7,500 organisms $/ \mathrm{ml}$. (Fig. 1B) the oxygen content in the medium began to decrease rapidly. Since at this time the culture volume was $1,400 \mathrm{ml}$., the total number of organisms was about $10 \times 10^{6}$. With a respiratory rate of $5 \mu \mathrm{l}$. oxygen $/ 10^{6}$ organisms $/ \mathrm{min}$, the respiratory capacity of the culture is about $50 \mu \mathrm{l} . \mathrm{O}_{2} / 10^{6}$ organisms $/ \mathrm{min}$. for $\log$ phase organisms. Ormsbee (1942) and Hamburger \& Zeuthen (1959) have reported values of $7 \cdot 2$ and $4 \cdot 8 \mu \mathrm{l} . \mathrm{O}_{2} / 10^{6}$ organisms $/ \mathrm{min}$. respectively for log phase organisms. Experimentally determined rates of diffusion of oxygen from air into still or slowly moving water are 0.03 to $0.08 \mathrm{~g} . / \mathrm{m}^{2} / \mathrm{hr}\left(=0.04\right.$ to $0.09 \mu \mathrm{l} . / \mathrm{cm} .{ }^{2} / \mathrm{min}$.) at $25^{\circ}$ and zero oxygen tension (Odum, 1956). The maximum amount of oxygen that could enter the culture (with a surface area of $450 \mathrm{~cm} .{ }^{2}$ ) would be $20-40 \mu l . / \mathrm{min}$. Thus already at a population density of 7500 organisms/ml., the respiratory capacity of the culture exceeds the maximum possible rate of diffusion of oxygen. The oxygen content of the 
medium was indeed decreasing at this culture density. During stationary phase at a population density of $\mathbf{9 0 , 0 0 0}$ organisms $/ \mathrm{ml}$., these organisms could respire at only about $5 \%$ of their potential, if the rate of diffusion is compared with the respiratory capacity $\left(650 \mu \mathrm{l} . \mathrm{O}_{2} / \mathrm{min}\right.$.) of the culture. In contrast, the oxygen content in the aerated culture at a population density of 90,000 organisms $/ \mathrm{ml}$. had just begun to decrease (Fig. 1 A).

\section{Cellular glycogen content and oxygen content of the medium throughout a growth cycle.}

Fourteen cultures were started simultaneously as described in the legend to Fig. 2. Each of the cultures was used for total count, determination of dissolved oxygen

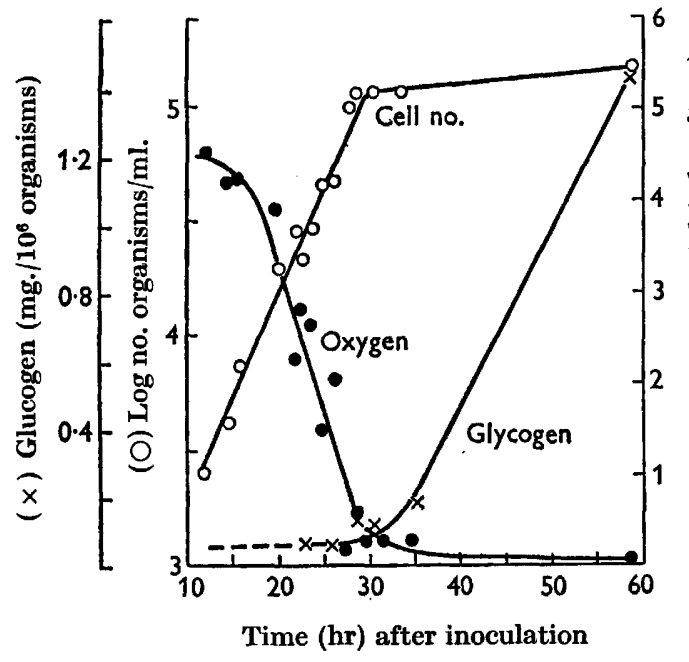

Fig. 2

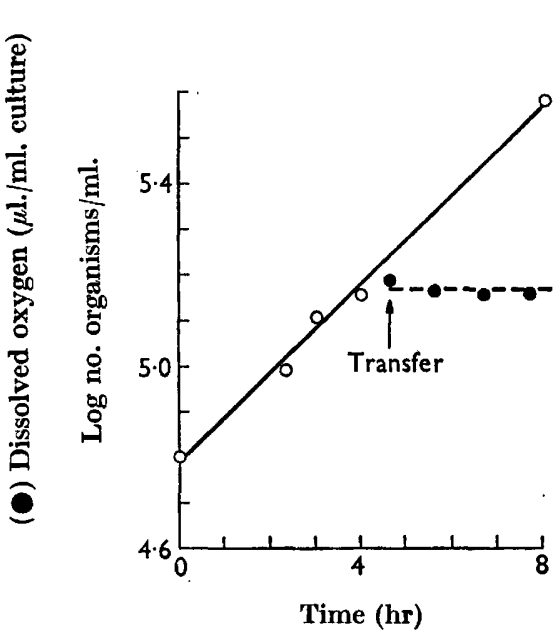

Fig. 3

Fig. 2. Cellular glycogen content and oxygen content of the medium during a growth cycle. Fourteen $500 \mathrm{ml}$. Erlenmeyer flasks, each containing $160 \mathrm{ml}$. medium, were inoculated (starting population, 800 organisms/ml.) and maintained at room temperature with very gentle shaking. At the times indicated, the dissolved oxygen in the medium, cellular glycogen, and population density (total count) were determined.

Fig. 3. Induction of stationary phase. Stationary phase was induced by transferring four $29 \mathrm{ml}$. samples of a well-shaken culture, growing exponentially in thin layer (in stainless steel tank), into four $125 \mathrm{ml}$. Erlenmeyer flasks, which were then maintained without further shaking. At $0,1,2$, and $3 \mathrm{hr}$ after transfer, samples were removed for counts (full circles). Shaking was continued in the remainder of the culture. The arrow denotes the time of transfer.

and glycogen content at the times indicated, ranging from $12 \mathrm{hr}(6600$ organisms/ $\mathrm{ml}$.) to $58 \mathrm{hr}(210,000$ organisms/ml.) after inoculation. At about $30 \mathrm{hr}$ after inoculation, when less than $0.5 \mu \mathrm{l} . \mathrm{O}_{2} / \mathrm{ml}$. was found in the medium, multiplication ceased and the glycogen content began to increase in those organisms. The stationary phase organisms contained 22 times as much glycogen as the log phase organisms. 


\section{Induction of stationary phase}

To study possible differences in metabolism between growing and non-growing organisms, a technique was developed for the rapid and reproducible induction of stationary phase. This was accomplished by transfer of well-shaken cultures, growing exponentially in shallow layers in the stainless steel tank, into smaller vessels, followed by maintenance without shaking. The results of such an experiment are shown in Fig. 3. At the time indicated by the arrow, four samples of culture were transferred at a population density of 140,000 organisms $/ \mathrm{ml}$. Using this figure and the new surface/volume ratio, it was calculated that respiration was limited to between 5 and $10 \%$ of the normal rate. During a 3-hr period following transfer (approximately one generation time in exponential growth phase) there was little increase in total numbers (0-20\%), while increase in protein ranged from 10 to $40 \%$ and glycogen, 50-300\% (5 experiments). Exponential multiplication in the tank was still observed at a population density of 370,000 organisms $/ \mathrm{ml}$. (Fig. 3).

\section{Glyconeogenic capacity before and after induction of stationary phase}

After transfer to conditions of restricted aeration, samples of culture were taken at the times indicated in Table 1 , tracer amounts of sodium acetate-2-14 $\mathrm{C}$ were added and shaken for $15 \mathrm{~min}$. Glycogen was isolated and the radioactivity determined. The results are shown in Table 1. In the untreated control cultures, the rate of

\section{Table 1. Incorporation of acetate-2-14 C into glycogen during induction of stationary phase}

Stationary phase was induced in part of an exponentially growing culture by transfer of $35 \mathrm{ml}$. portions of culture into $125 \mathrm{ml}$. conical flasks, followed by maintenance without shaking. The remainder of the culture was shaken to permit growth to continue. Population density at the time of transfer was 120,000 organisms $/ \mathrm{ml}$. At the times indicated, $25 \mathrm{ml}$. portions of culture were shaken for $15 \mathrm{~min}$. with $1 \mu \mathrm{c}$. of acetate-2-14 $\mathrm{C}$ (sp.act. $20.5 \mathrm{mc} . / \mu \mathrm{mole})$.

$\begin{array}{ccc}\text { Hours after } & \begin{array}{c}\text { Incorporation of } \\ \text { acetate-2-14C } \\ \text { into glycogen } \\ \text { (counts/min./ }\end{array} \\ \text { Log phase control } & 0 & \begin{array}{c}727 \\ \text { million organisms) }\end{array} \\ \text { Non-shaken culture } & 1 \cdot 5 & 1040 \\ & 3 & 1630 \\ & 0 & \mathbf{7 2 7} \\ & \mathbf{1 . 5} & \mathbf{1 4 6 0}\end{array}$

incorporation of the label was $2 \cdot 2$ times in the 3 -hr sample as compared to the zero hour sample. In the stationary culture, however, the comparable increase was $7 \cdot 7$ times. In other experiments, values up to 20 times were obtained. Similar results were observed when organisms were washed and resuspended in inorganic buffer before incubation with labelled acetate. However, when incorporation of glucose- ${ }^{14} \mathrm{C}$ was tested under the same conditions, the rates at zero and $3 \mathrm{hr}$ after transfer were almost identical. 
The results show that limited aeration inhibited growth and division but increased the ability of the organisms to incorporate carbon from acetate into glycogen. Therefore, stationary and log phase cultures were used for the following further comparisons: (1) rates of glyconeogenesis were recorded in cultures as well as in washed suspensions with and without added acetate; (2) the incorporation of acetate-2-14 $\mathrm{C}$ was studied at tracer concentrations only, and together with acetate at substrate concentrations. Results of these experiments are shown in Fig. 4. All stationary phase cultures tested showed an increased rate of glyconeogenesis in culture (Fig. 4A) were 0.08 and $0.26 \mu$ mole glucose $/ \mathrm{mg}$. protein $/ \mathrm{hr}$ in $\log$ and
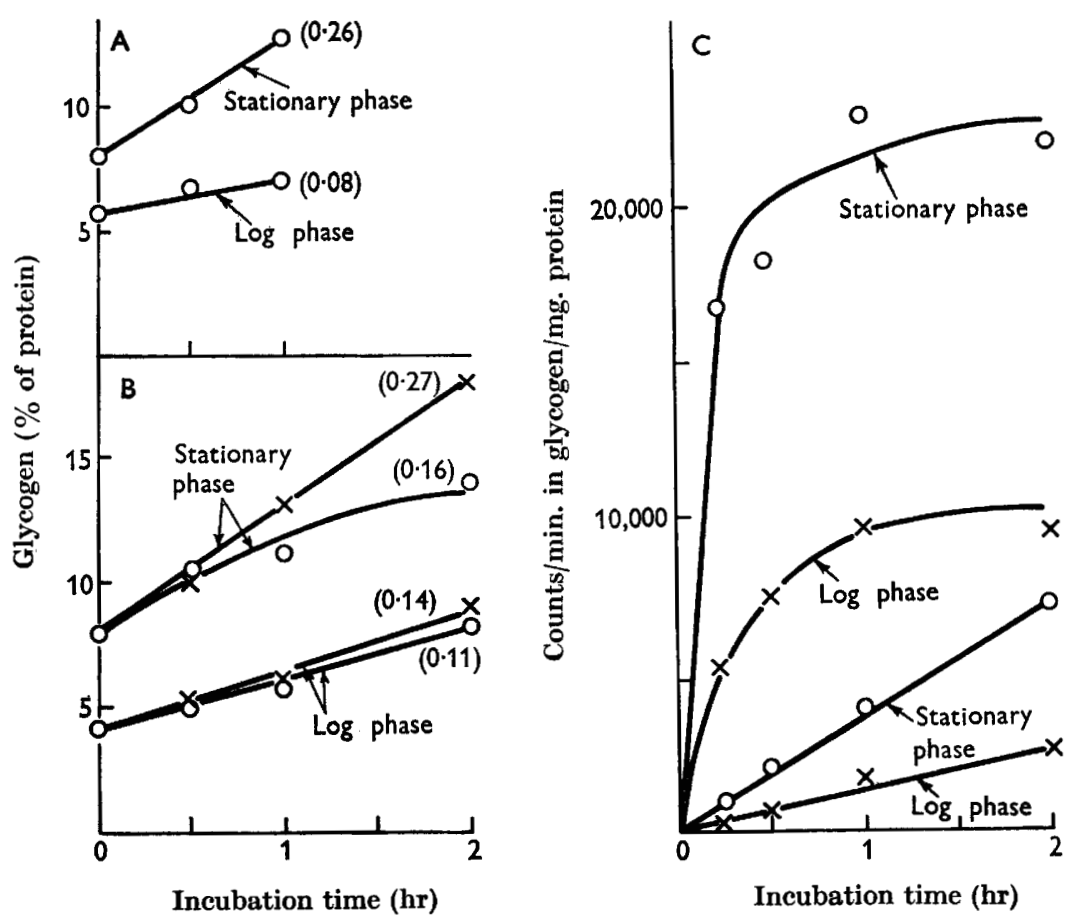

Fig. 4. Rate of glyconeogenesis before and after induction of stationary phase. Stationary phase was induced by transferring $110 \mathrm{ml}$. portions of an exponentially growing culture into $500 \mathrm{ml}$. conical flasks, which were maintained for $3 \mathrm{hr}$ without shaking. Population density at the time of transfer was 116,000 organisms/ml. At zero and $3 \mathrm{hr}$ after transfer, glyconeogenic capacity was tested by shaking portions of culture or of washed suspensions. This is referred to as incubation time on the abscissae. A. Glyconeogenesis in culture. Twenty ml. portions of culture were transferred to $250 \mathrm{ml}$. conical flasks and shaken for $1 \mathrm{hr}$ at $29^{\circ}$. Glycogen values are based on the amount of protein present at the start of the incubation period. The figures in parentheses give $\mu$ mole glucose/mg. protein/hr measured over a $1 \mathrm{hr}$ period. B. Glyconeogenesis in washed organisms. Organisms were removed from culture medium, washed 3 times and suspended in Ryley's Ringer phosphate buffer. Two and s half ml. portions of the washed suspensions, containing approximately $1 \mathrm{mg}$. protein $/ \mathrm{ml}$., were shaken at $29^{\circ}$ in $50 \mathrm{ml}$. flasks, in the presence $(x-x)$ or absence $(0-0)$ of $0.1 \%(w / v)$ sodium acetate. Sodium $2-14 \mathrm{C}$ acetate $(172,000$ counts/min. under the test conditions) was added to each flask. The figures in parentheses give $\mu$ mole glucose/mg. protein/hr measured over a $2 \mathrm{hr}$ period. C. Incorporation of acetate-2-14 $\mathrm{C}$ into glycogen in washed suspensions. Lower two curves show incorporation in the presence of $0.1 \%$ sodium acetate, upper two curves, the incorporation when acetate was added at tracer concentrations only. $x-x, \log$ phase; $0-0$, stationary phase. 
stationary phase, respectively. In repeated experiments, comparable values ranged from zero to 0.22 in log phase and from 0.21 to 0.55 in stationary phase. Washed organisms (Fig. 4B) showed the same difference. The rate of glycogen synthesis in log phase organisms was $0.11 \mu$ mole glucose $/ \mathrm{mg}$. protein/hr and in the stationary phase organisms it was $0 \cdot 16 \mu$ mole glucose $/ \mathrm{mg}$. protein $/ \mathrm{hr}$. In the presence of $0.1 \%$ $(\mathrm{w} / \mathrm{v})$ sodium acetate, however, a marked stimulation was observed in stationary phase organisms, $\mathbf{0} \cdot \mathbf{2 7}$, but not so in log phase organisms $(0 \cdot 14 \mu \mathrm{mole}$ glucose/mg. protein/hr). This increased rate of glyconeogenesis in stationary phase organisms is further substantiated by the rate of incorporation of labelled acetate into glycogen (Fig. 4C). After $2 \mathrm{hr}$ of incubation, more than twice the label was found in stationary phase organisms than in log phase organisms. This is the case whether organisms were incubated with trace amounts of sodium acetate (upper two curves, Fig. 4C), or with $0 \cdot 1 \%$ (lower two curves, Fig. 4C).

\section{DISCUSSION}

The results presented in this paper are in agreement with other reports which show that washed stationary phase suspensions of Tetrahymena pyriformis may have an appreciable endogenous rate of glyconeogenesis (Hogg \& Wagner, 1956; Warnock \& van Eys, 1962). The chemical nature of the precursors for glyconeogenesis cannot be given with certainty. Hogg \& Wagner (1956) reported a decrease in intracellular protein and lipid with a concomitant increase in glycogen; a respiratory quotient of $\mathbf{0 . 5 5}$ and the ability of fatty acids to stimulate glyconeogenesis suggested that lipids are the main precursors. Warnock \& van Eys (1962) showed a considerable increase in glycogen content in washed cells with a significant loss in protein. In cultures grown in proteose peptone, the ultimate precursors for glycogen must be amino acids. It is not known, however, whether these are converted to carbohydrates directly or via fatty acids.

Although the factors which lead to the onset of stationary phase have not been unequivocally determined, a deficiency in the amount of oxygen available to the organisms was clearly related to the onset of stationary phase. In cultures grown with little or no agitation, oxygen became depleted from the medium at low population densities, and this was followed quite soon by cessation of division. In wellshaken cultures, however, oxygen disappeared at much higher population densities and division again ceased, following a somewhat longer transition period. Once detectable oxygen had disappeared from the medium, respiration of the culture remained constant at a rate determined by the rate of diffusion of oxygen into the culture. Consequently, the respiration rate per organism must decrease until culture growth ceases. In some of the stationary phase cultures mentioned here, the respiratory rate was only about $5 \%$ of the organisms' capacity. That Tetrahymena will use all available free oxygen in the medium has already been reported by Baker \& Baumberger (1941).

The close correlation between decreased oxygen tension in the medium and the onset of stationary phase does not exclude possible roles other gases might have in the onset of stationary phase and/or the induction of glyconeogenic capacity. The condition used here to limit the exchange of oxygen into the medium would also limit the diffusion of carbon dioxide and ammonia from the culture. Preliminary 
experiments indicate that carbon dioxide at high partial pressure $(25 \%)$ can rapidly induce stationary phase (Drs A. M. Elliott and I. J. Bak, personal communication) although no increase in glyconeogenic capacity occurred (Levy \& Hogg, unpublished data).

A possible biological significance of the results has been suggested by Dr J. F. Hogg (personal communication). Photosynthetic organisms in the natural habitat of Tetrahymena cease oxygen production during the night. Consequently, the falling oxygen tension may lead to an increase in glyconeogenesis from intracellular reserves. This makes possible survival of the organism under temporary anaerobic conditions, where metabolism depends on glycogen fermentation.

Support of Grant no. G-18554 from the National Science Foundation, Washington, D.C., U.S.A., is gratefully acknowledged. The authors thank Dr M. S. Gordon (Department of Zoology, U.C.L.A.) for making available the apparatus for the determination of dissolved oxygen, and Dr J. F. Hogg (Department of Biological Chemistry, University of Michigan) for valuable suggestions in the course of this work.

Parts of this paper were submitted by M. R. L. to the graduate school of the University of California, Los Angeles, in partial fulfilment of the degree of Doctor of Philosophy.

\section{REFERENCES}

Baker, E. G. S. \& Baumberger, J. P. (1941). The respiration rate and the cytochrome content of a cilate protozoan (Tetrahymena gelii). J. cell. comp. Physiol. 17, 285.

Chov, S. C. \& Goldstein, A. (1960). Chromogenic groupings in the Lowry protein determination. Biochem. J. 75, 109.

Dagley, S. \& Dawes, E. A. (1949). Factors influencing the polysaccharide content of Escherichia coli. Biochem. J. 45, 331.

Duguid, J. P. \& Wilkinson, J. F. (1953). The influence of cultural conditions on polysaccharide production by Aerobacter aerogenes. J. gen. Microbiol. 9, 174.

Good, C. A., Kramer, H. \& Somogyi, M. (1933). The determination of glycogen. J. biol. Chem. 100, 485.

Hamburger, K. \& Zeuthen, E. (1959). Synchronous division in Tetrahymena pyriformis as studied in an inorganic medium. The effect of 2,4-dinitrophenol. Exp. Cell Res. 13, 443.

Hogg, J. F. \& Kornberg, H. L. (1963). The metabolism of $\mathrm{C}_{2}$-compounds in microorganisms. 9. Role of the glyoxylate cycle in protozoal glyconeogenesis. Biochem. $J$. 86,462 .

Hogg, J. F. \& Wagner, C. (1956). The glycogen metabolism of Tetrahymena pyriformis. Fed. Proc. 15, 275.

Holme, T. \& Palmstierna, H. (1955). The content of polyglucose of glycogenic nature in E. coli $\mathbf{B}$ during growth in media deficient in nitrogen and carbon. Acta chem. scand. 9, 1020.

Holme, T. \& Palmstierna, H. (1956). Changes in glycogen and nitrogen-containing compounds in Escherichia coli $\mathbf{B}$ during growth in different media. 1. Nitrogen and carbon starvation. Acta chem. scand. 10, 578.

KIDDER, G. W. \& Dewey, V. C. (1951). The biochemistry of ciliates in pure culture. In Biochemistry and Physiology of Protozoa. Ed. by A. Lwoff. New York: Academic Press.

Levy, M. R., Scherbaum, O. H. \& Hogg, J. F. (1964). Activation of glyconeogenesis in Tetrahymena pyriformis. Fed. Proc. 23, 320.

Manners, D. J. \& Ryuey, J. F. (1952). Studies on the metabolism of protozoa. 2. The glycogen of the ciliate Tetrahymena pyriformis (Glaucoma pyriformis). Biochem. J. 52. 480 . 
Morris, D. L. (1948). Quantitative determination of carbohydrates with Dreywood's anthrone reagent. Science, 107, 254.

Odum, H. T. (1956). Primary production in flowing waters. Limnol. Oceanogr. 1, 102.

Ormsbee, R. A. (1942). Normal growth and respiration of Tetrahymena gelii. Biol. Bull.. Woods Hole, 82, 423.

RYLEY, J. F. (1952). Studies on the metabolism of protozoa. 3. Metabolism of the ciliate Tetrahymena pyriformis (Glaucoma pyriformis). Biochem. J. 52, 483.

SCHERBAUM, O. H. (1957). The application of a standard counting method in estimation of growth in normal and heat-treated cultures of Tetrahymena pyriformis. Acta path. microbiol. scand. $40,7$.

Scherbaum, O. H., James, T. W. \& JAhN, T. L. (1959). The amino acid composition in relation to cell growth and cell division in synchronized cultures of Tetrahymena pyriformis. J. cell. comp. Physiol. 53, 119.

Scholander, P. F., van Dam, L., Claff, C. L. \& Kanwisher, J. W. (1955). Microgasometric determination of dissolved oxygen and nitrogen. Biol. Bull., Woods Hole, 109, 328.

WARNOCK, L. G. \& vAN EYS, J. (1962). Normal carbohydrate metabolism in Tetrahymena pyriformis. J. cell. comp. Physiol. 60, 53.

WiLkinson, J. F. (1959). The problem of energy-storage compounds in bacteria. Exp. Cell Res. (Suppl. 7), 111.

WiLkinson, J. F. (1963). Carbon and energy storage in bacteria. J. gen. Microbiol. 32, 171. 